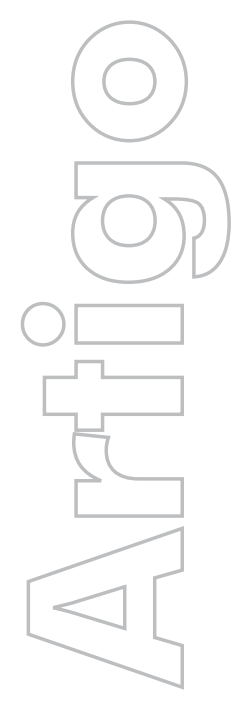

\title{
Identificação e análise da estrutura espacial dos extremos de temperatura do ar na bacia do rio Paranaíba por meio da técnica de anos-padrão
}

\author{
Arlei Teodoro de Queiroz \\ UnB \\ Ercília Torres Steinke \\ UnB
}

\section{revista}

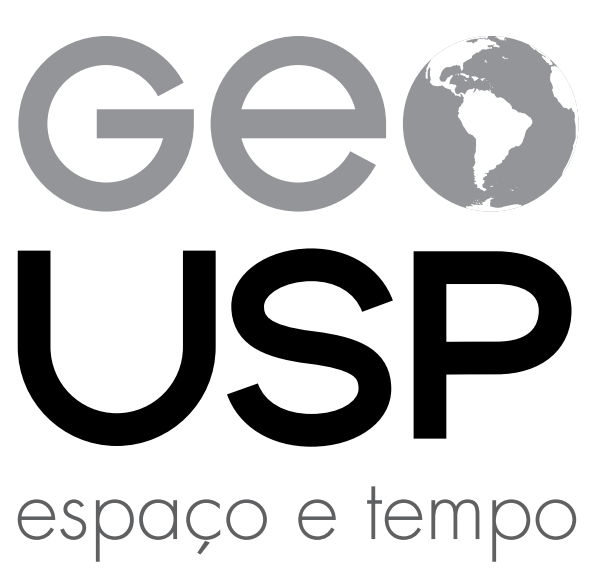

Volume $21 \cdot n^{\circ} 1(2017)$

ISSN 2179-0892
Como citar este artigo:

QUEIROZ, A. T.; STEINKE, E. T. Identificação e análise da estrutura espacial dos extremos de temperatura do ar na bacia do rio Paranaíba por meio da técnica de anos-padrão. Geousp - Espaço e Tempo (Online), v. 21, n. 1, p. 217-238, abril. 2017. ISSN 2179-0892.

Disponível em: < http://www.revistas.usp.br/geousp/ article/view/107571>. doi: 10.11606/issn.2179-0892. geousp.2017.107571.

\section{(c) (i) (8)}

Este artigo está licenciado sob a Creative Commons Attribution 4.0 License. 


\section{Identificação e análise da estrutura espacial dos extremos de temperatura do ar na bacia do rio Paranaíba por meio da técnica de anos-padrão}

\section{Resumo}

Este trabalho procurou identificar e analisar os extremos de temperatura do ar registrados na bacia do rio Paranaíba, bem como a variação percentual de seus extremos em relação à média, seguindo a metodologia de anos-padrão sugerida por Tavares (1976). Os resultados foram espacializados em mapas, a fim de mostrar a espacialização, consequência da variação estrutura espacial desse parâmetro. Observou-se que, no período estudado, a maior amplitude térmica na bacia foi nas porções sul e oeste, tendo sido registradas as temperaturas máximas e mínimas anuais. Essa dinâmica da bacia pode ser compreendida por meio de sua hipsometria, com altitude mais baixa na porção sudoeste, na direção de seu exutório, tanto quanto pela dinâmica das massas de ar na região.

Palavras-chave: Temperatura extrema. Bacia do rio Paranaíba. Variação percentual. Estrutura espacial. Anos-padrão.

\section{Identification and analysis of the spatial structure of the air temperature extremes in the Paranaíba watershed through of technical of years standard}

\footnotetext{
Abstract

This study aimed to identify and analyze the extremes of air temperature registered in the Paranaiba watershed, as well as the percentage variation of its extremes in relation to the average, following the methodology of standard years highlighted by Tavares (1976). The results were spatialized on maps, with the aim of show the spatialization, due to fluctuations spatial
} 
structure of such parameter. Was observed that, in the period studied, the highest amplitude thermal in the watershed occurred in the parts southern and western, being registered both the highest annual temperatures, as the minors. Such dynamics of the watershed can be understood by means of its hypsometry, with lowest elevation in the southwest part, toward from its river mouth, as much as the dynamics of air masses actants in the region.

Keywords: Extreme temperature. Paranaíba watershed. Percentage variation. Spatial structure. Standard years.

\section{Introdução}

O conhecimento da Climatologia de uma região constitui um importante fator para o estudo do ambiente, pois sua dinâmica interfere nos processos hidrológicos, de formação do relevo e dos solos, e crescimento e desenvolvimento da vegetação, entre outras ações que interferem na paisagem. Além disso, o clima é fator condicionante para a implantação e desenvolvimento de diversas atividades econômicas, com destaque para as que são vinculadas ao setor agropecuário.

$\mathrm{Na}$ região do Brasil Central, no que tange a relação entre o clima e a questão socioeconômica verifica-se que os principais problemas referem-se a eventos e/ ou episódios extremos, sobretudo, quanto a períodos de escassez pluviométrica ou precipitações concentradas. Esses eventos e/ou episódios causam muitos prejuízos, desde os financeiros até eventuais óbitos.

Entre as diversas técnicas que podem ser empregadas para o estudo desta temática, a metodologia que defini os anos que compõem o período de estudo em padrão habituais e excepcionais é comumente empregada na climatologia geográfica.

Tendo como base os estudos sobre anos-padrão para análise dos dados pluviométricos, a presente investigação teve intenção de realizar uma experiência para verificar se a técnica de anos-padrão pode ser adaptada para dados de temperatura do ar, produzindo informações que possam representar a realidade da dinâmica desse parâmetro.

Nesse contexto, a presente investigação teve como objetivo identificar e analisar a distribuição espacial das temperaturas mínimas, máximas e médias diárias do ar registradas na bacia hidrográfica do rio Paranaíba, bem como realizar uma análise prévia dos extremos de temperatura do ar por meio de sua variação percentual em relação à média, adaptando a metodologia de anos-padrão destacada por Tavares (1976), para os dados de temperatura. Essa análise preliminar buscou identificar os extremos de temperatura do ar que ocorreram na bacia do rio Paranaíba, no período compreendido entre 1980 e 2013, com o intuito de auxiliar o planejamento agropecuário, uma vez que extremos de temperatura do ar podem gerar problemas nos processo de crescimento 
das plantas, pois todos os cultivos têm limites térmicos mínimos, ótimos e máximos para cada um de seus estágios de crescimento.

\section{Fundamentação metodológica}

No que diz respeito às influências dos extremos de temperatura do ar e da umidade relativa sobre os seres humanos, alguns autores destacam a dificuldade de adaptação dos mesmos, sobretudo quando ocorrem oscilações meteorológicas em curta escala temporal, corroborando para a ocorrência de algumas doenças que podem culminar até mesmo, no óbito de pessoas. Nesse sentido, Mendes (2001, p. 3) afirma que:

Os fenômenos naturais, principalmente os relacionados com a atmosfera, quando se apresentam como eventos extremos, como calor ou frio em excesso, ou ainda estiagens ou precipitações fora dos padrões normais, levam sociedades despreparadas a enfrentar sérios problemas, muitas vezes catastróficos, que repercutem negativamente no bem-estar das populações, principalmente das que habitam as grandes cidades (Mendes, 2001, p. 3).

Ao tratar das variáveis termo-higrométricas, Monteiro e Carvalho (2013, p. 107) destacam que "[...] os seres humanos são das espécies que têm limiares de resistência e adaptabilidade mais estreitos ao contexto termo-higrométrico indoor e outdoor [...]”.

Prosseguindo com a descrição referente a resistência humana aos extremos termohigrométricos, cabe aqui salientar a contribuição de Olgyay (1968' apud Andrade, 1996) para a compreensão destes extremos em climas quentes, quando o autor desenvolveu um trabalho para a Colômbia.

Os novos estudos levaram em consideração a aclimatação dos habitantes desta região. Olgyay (1968) adotou parâmetros para definir a zona de conforto, baseando-se na temperatura média de verão, obtendo para cada cidade uma zona de conforto própria.

O avanço obtido por Olgyay (1968), nesta nova carta, encontra-se na sua maior flexibilidade, onde se consegue analisar tanto climas temperados quanto quentes e úmidos, dependendo da zona de conforto a ser adotada. Nesta nova carta os limites adotados na prática para regiões úmidas foram de 20 a $80 \%$ de umidade relativa, e as temperaturas do bulbo seco limites para a zona de conforto foram de $18,3^{\circ} \mathrm{C}$ e $29,5^{\circ} \mathrm{C}$, podendo ser adotados valores intermediários, conforme a temperatura média da região em estudo (Andrade, 1996, p. 19).

1 OLGYAY, V. Clima y Arquitectura en Colombia. Cali, CO: Universidade del Valle, 1968. 
Tendo em vista o que foi relatado sobre temperatura e umidade relativa, vale salientar que os procedimentos metodológicos para elaborar um trabalho sobre essas variáveis, assim como o clima de uma região e suas variações, tem como uma das etapas primordiais para a realização do mesmo a coleta e análise de dados meteorológicos registrados em uma série histórica. Segundo Silvestre, Sant'anna Neto e Flores (2013) classificar um conjunto de dados, em um determinado número de classes, no momento de se definir valores como sendo habituais ou extremos constitui-se em um problema muito comum encontrado pelos estudiosos do clima.

A escolha de anos-padrão como forma de analisar a dinâmica atmosférica teve início nas concepções de Monteiro (1973), ao propor critérios para a escolha de anos-padrão, executando a técnica de análise rítmica, que leva em conta a concepção sorreana do clima. Monteiro (1973) ressalta que o tratamento dinâmico qualitativo utilizado, ao se lançar mão da técnica de anos-padrão, trabalha com amostras cronológicas do tempo atmosférico que melhor representem a realidade climática.

A técnica dos anos-padrão possibilita a separação de anos que apresentem características semelhantes quanto a uma determinada variável, de forma que esses possam ser considerados como um grupo com características semelhantes; e posteriormente eleger um ano padrão para representar cada grupo. Boin (2000, p. 131) acredita que:

O uso de "anos-padrão", com base na da análise rítmica diária, proposta por Monteiro (1971a, ${ }^{2}$ 1973), e tão empregado como forma de análise do conhecimento dinâmico do clima, é a técnica capaz de alcançar a compreensão real do clima, sem necessitar da representação de toda a série estudada, o que dependeria de um grande número de dados, muitas vezes inexistentes. Outro fator que impossibilitaria o emprego da representação de toda a série estudada seria, ainda, o grande número de sínteses, o que tornaria difícil a análise e interpretação dos dados utilizados (Boin, 2000, p. 131).

Várias técnicas podem ser empregadas para a classificação de anos-padrão, seja de temperatura do ar, precipitação ou outro elemento climático de interesse. Tavares (1976), com o objetivo de analisar os dados de precipitação pluvial de Campinas, no período de 1961 a 1970, desenvolveu uma técnica de agrupamento para definir anos-padrão, que é bastante utilizada pelos geógrafos estudiosos do clima. A seguir encontra-se uma síntese da metodologia utilizada por Tavares (1976).

Primeiramente, os dados mensais de precipitação foram agrupados em períodos

2 MONTEIRO, C. A. F. Análise Rítmica em Climatologia. Climatologia, São Paulo: IGEOG/USP, n.1, 1971. 
trimestrais, correspondentes às estações do ano. Após esse agrupamento, a média para cada uma das quatro estações do ano foi calculada para o período de estudo. Em seguida foram calculados: o desvio percentual de cada estação do ano em relação aos dados médios obtidos e o coeficiente de similaridade multidimensional entre os desvios percentuais. Os resultados foram organizados em formato de matriz à qual se aplica uma técnica de agrupamento hierárquica por pares recíprocos (Diniz, 1971; Sanchez, 1972). O resultado final da aplicação da técnica é apresentado em um gráfico denominado dendrograma ou árvore de ligação, a partir do qual se pode observar o agrupamento dos anos considerados, e o nível de perda de detalhe (\%) em que eles foram realizados. Os anos da série considerada são classificados em anos-padrão secos, normais e chuvosos, selecionando-se um ano para cada um dos grupos de interesse para dar continuidade à análise escolhida.

A Figura 1 apresenta um fluxograma metodológico, sendo possível acompanhar o passo a passo da metodologia de anos-padrão descrita por Tavares (1976).

\section{Figura 1}

Fluxograma da metodologia de anos-padrão descrita por Tavares (1976)

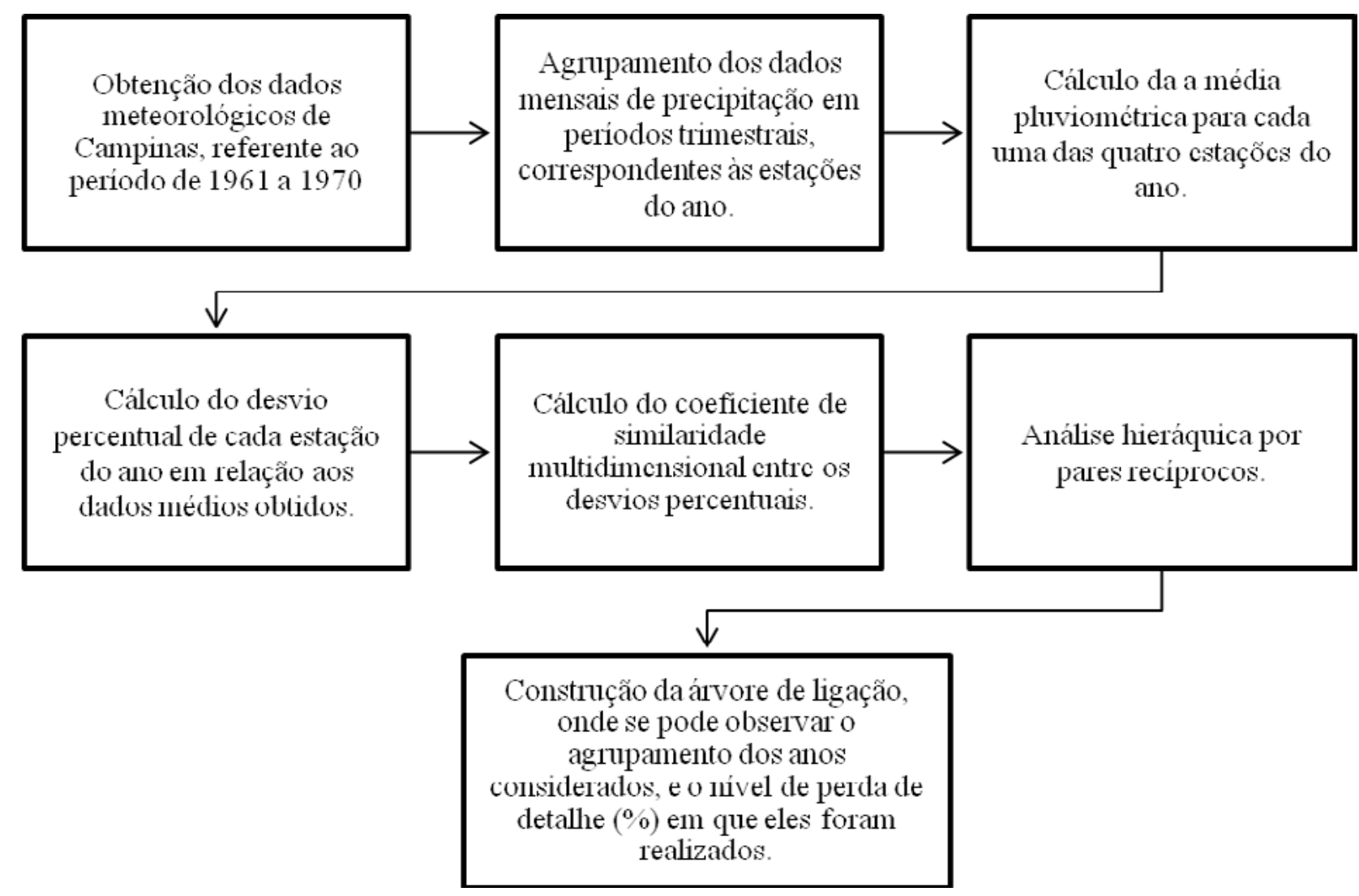

elaboração: Os autores. 
A partir de então diversos estudos passaram a utilizar essa técnica, seja da mesma forma que Tavares (1976), seja por meio de outras técnicas estatísticas. Silvestre, Sant'anna Neto e Flores (2013), por exemplo, compararam cinco técnicas que podem ser utilizadas para classificar os anos de estudo em anos-padrão: a fórmula de Sturges, empregada para definir o número de classes e a amplitude dos intervalos das classes; o box plot, que utiliza os percentis de 5\%, 25\%,75\% e 95\%; o quantis, que considera os percentis de 15\%,35\%,65\%,85\%; o desvio-padrão em relação à média e a análise de agrupamentos, para a qual foram considerados seis métodos de agrupamentos hierárquicos denominados ligação simples, ligação completa, ligação média, ligação mediana, ligação de centroides e ward. $\bigcirc$ resultado mostrou que entre os métodos com limites de classes rígidos, como é o caso das técnicas Sturges, box plot, quantis e desvio, as quais definem valores pré-determinados para os limites das classes, têm desvantagem sobre os métodos de agrupamentos hierárquicos, que tem maior flexibilidade nesse aspecto, permitindo que pontos próximos entre si permaneçam na mesma classe, ao invés de provocar uma separação abrupta entre eles em duas classes distintas e vizinhas.

Schneider e Silva (2014) realizaram um trabalho em que demonstram o resultado da aplicação do método estatístico box plot para a identificação de anos-padrão secos, chuvosos e habituais, de uma série histórica (1980-2012) de dados pluviométricos da microrregião de Dourados-MS. Os resultados mostraram que a técnica box plot permitiu identificar e classificar os anos-padrão em cinco categorias: habitual, seco, chuvoso, superseco e superchuvoso. A classificação demonstrou-se, assim, eficiente e convergente aos objetivos da pesquisa, que visou compreender a variabilidade e o regime das chuvas em Dourados.

\section{Área de estudo}

A bacia hidrográfica do rio Paranaíba está inserida na região do Brasil Central, e é parte integrante da região hidrográfica do Paraná (Figura 2) e abrange parte do território de três estados (Goiás, Minas Gerais e Mato Grosso do Sul) e o Distrito Federal, mais especificamente: a região centro-sul do estado de Goiás, grande parte da região oeste de Minas Gerais e uma parcela do nordeste do Mato Grosso do Sul, além de grande parte do território do Distrito Federal. 


\section{Figura 2}

\section{Localização da bacia do rio Paranaíba na região hidrográfica do Paraná}

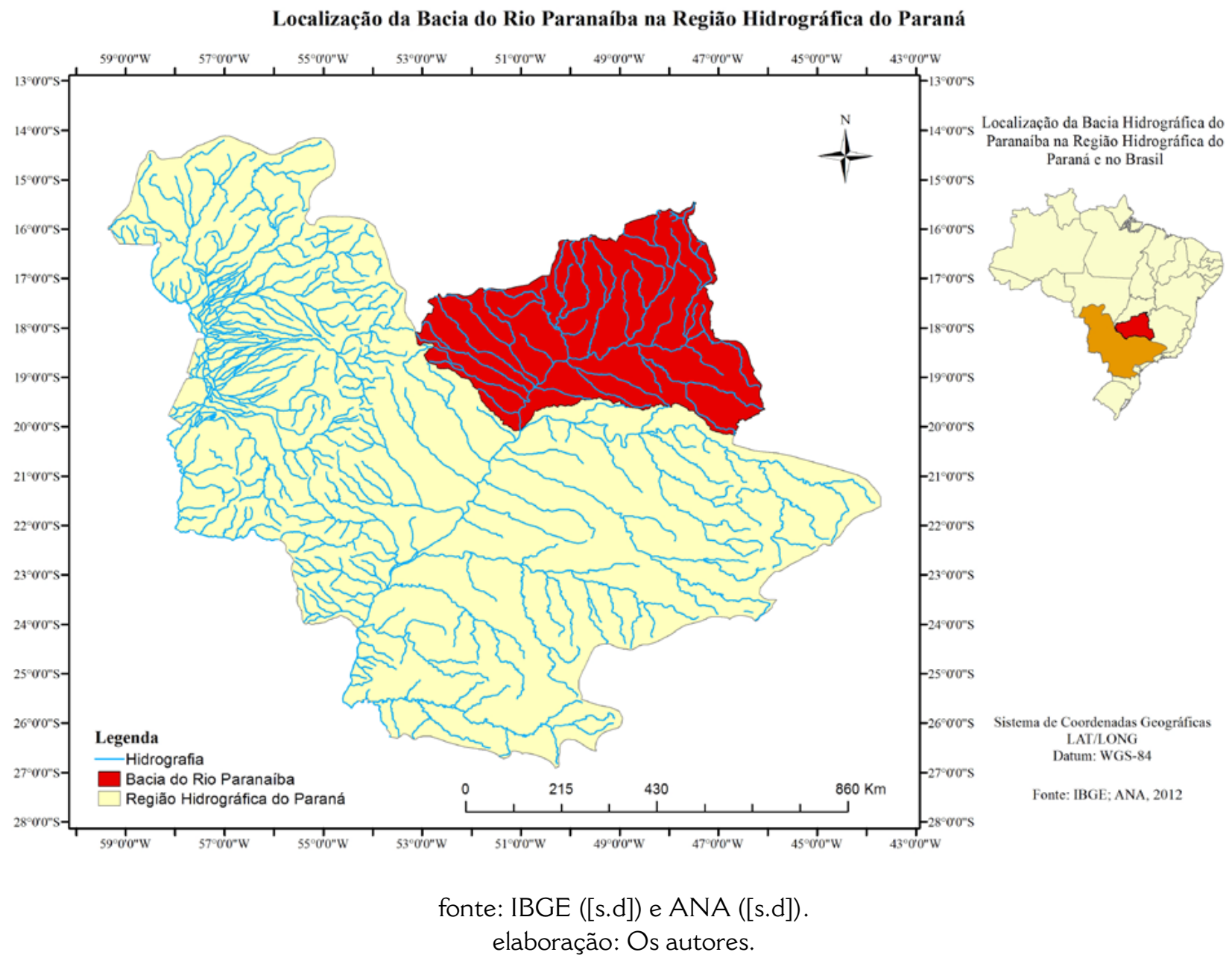

O clima é caracterizado por duas estações, verão quente e chuvoso e inverno seco e com temperaturas amenas. Esta sazonalidade climática da região com dois períodos extremos ao longo do ano provoca desconfor to humano, sobretudo os eventos e episódios relacionados a fenômenos de maior intensidade (amplitude térmica e higrométrica alta, calor, baixa umidade relativa, precipitação concentrada, estiagens etc.), tendo em vista, como já citado os estreitos limiares de resistência do ser humano as variações e extremos termo-higrométricos. No verão, destaca-se a atuação da massa Equatorial Continental $(\mathrm{mEc})$, que atraída pelos sistemas de baixa pressão do interior do continente, tende a avançar do NW, ora para SE, ora para ESE, atingindo a região Centro-Oeste, onde provoca elevação das temperaturas, sendo responsável ainda pelo aumento da umidade e das precipitações (Barros, 2003). Já no inverno, há o avanço de dois sistemas principais: massa tropical Atlântica Continentalizada ( $\mathrm{mTac}$ ), responsável por dias de temperatura elevadas e baixa umidade relativa do ar, e a Massa Polar Atlântica ( $\mathrm{mPa}$ ), formadora de frentes frias que provocam chuvas na região (Mendes; Queiroz, 2011).

A maior parte bacia é caracterizada pela ocorrência do bioma do Cerrado, segundo 
o IBGE ([s.d]), sendo que próximo às margens do rio Paranaíba, sobretudo a partir da sua confluência com o rio Araguari, nota-se a presença do bioma da Mata Atlântica. Destaca-se que a maior parte da vegetação natural das áreas dos dois biomas na bacia já foi desmatada.

O relevo da bacia do rio Paranaíba faz parte de um conjunto de formas denominado por Ab'Sáber (2003) Domínio dos Chapadões Tropicais do Brasil Central. Esse relevo vem sendo elaborado desde o Terciário, e durante o Quartenário, pelos processos morfoclimáticos, os quais propiciam extensas pediplanações, pedimentações, laterizações e dissecações, levando o relevo a ter as formas atuais.

\section{Figura 3}

\section{Mapa de hipsometria da bacia do rio Paranaíba}

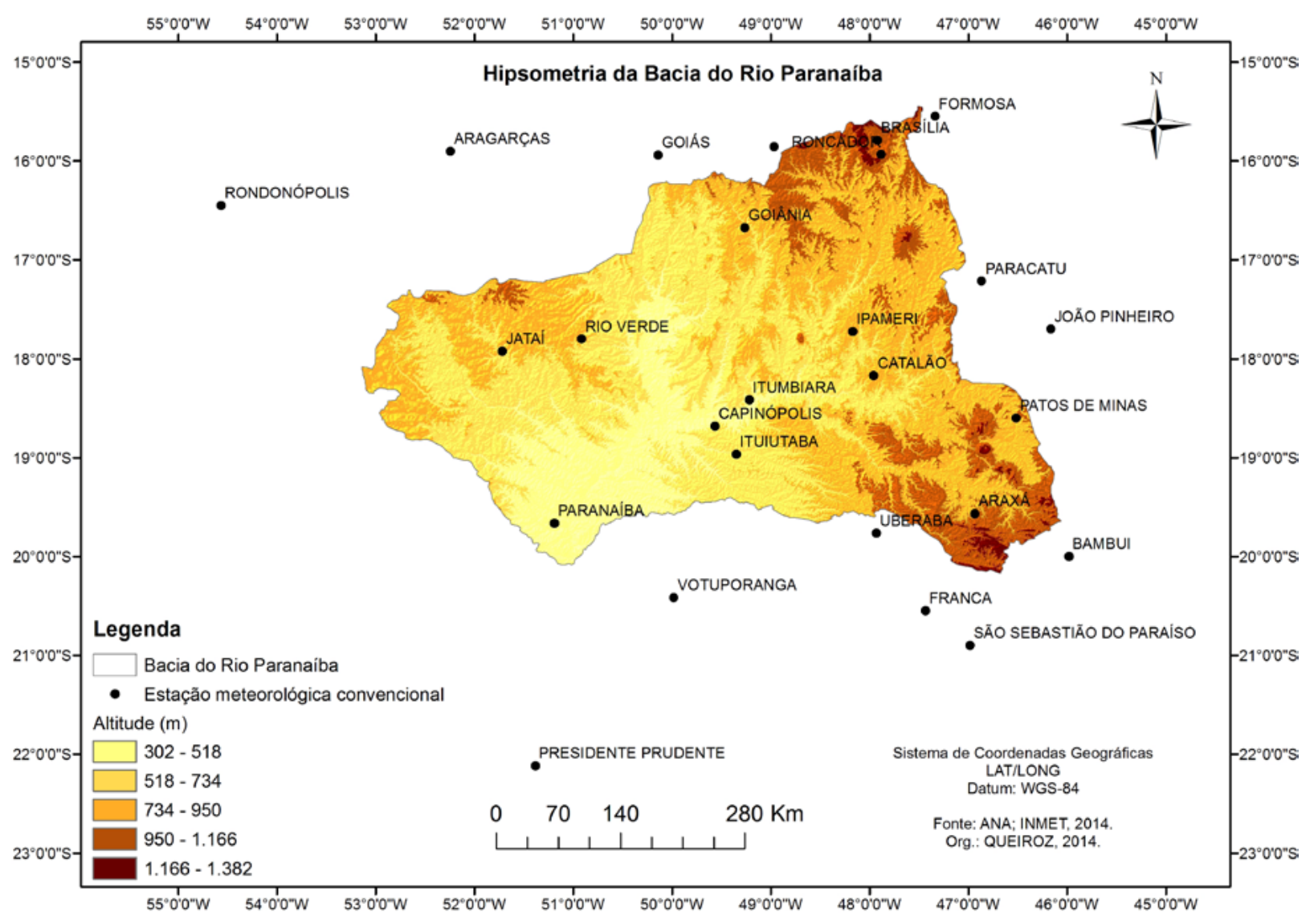

fonte: ANA ([s.d]), IBGE ([s.d]) e SRTM-Embrapa (Miranda, 2005).

elaboração: Os autores.

Na Figura 3, verifica-se que as maiores altitudes encontram-se na porção leste da bacia, sobretudo nos setores nordeste e sudeste (áreas das nascentes dos grandes rios). Já as menores altitudes encontram-se na porção sudoeste da bacia, no exutório do rio Paranaíba (confluência dos rios Paranaíba e Grande).

$\mathrm{Na}$ bacia do Paranaíba a atividade econômica mais expressiva é produção agropecuária no país (produção agrícola de soja, milho, cana-de-açúcar, entre outras 
culturas e a pecuária, principalmente, com rebanho bovino de corte e leite), conforme destacado no Plano de Recursos Hídricos da bacia (ANA, 2013). Tendo em vista a interdependência destas atividades junto as variáveis climáticas, faz necessário o estudo dos extremos de temperatura do ar, uma vez que os resultados podem ser utilizados como subsídio para as ações de planejamento, relacionadas ao conforto térmico animal e adequação as particularidades térmicas das diferentes culturas. Associada a esta produção agropecuária estão instaladas, na bacia, várias indústrias de beneficiamento destes produtos. Vale ressaltar a influência exercida pelas cidades de Brasília, Goiânia e Uberlândia, polos regionais com grande relevância tanto na prestação de serviços como na venda de produtos para as atividades exercidas na bacia, bem como para servir a população regional.

\section{Procedimentos metodológicos}

Para essa investigação foram obtidos, junto ao Instituto Nacional de Meteorologia (INMET), dados diários de temperatura do ar mínima, máxima e média diárias de 13 estações meteorológicas convencionais dentro dos limites da bacia em estudo e 13 em seu entorno, no período de 1980 a 2013, para triangulação e elaboração dos mapas de isotermas.

trabalho foi realizado em 4 etapas mostradas no fluxograma a seguir (Figura 4).

\section{Figura 4}

Fluxograma dos procedimentos metodológicos

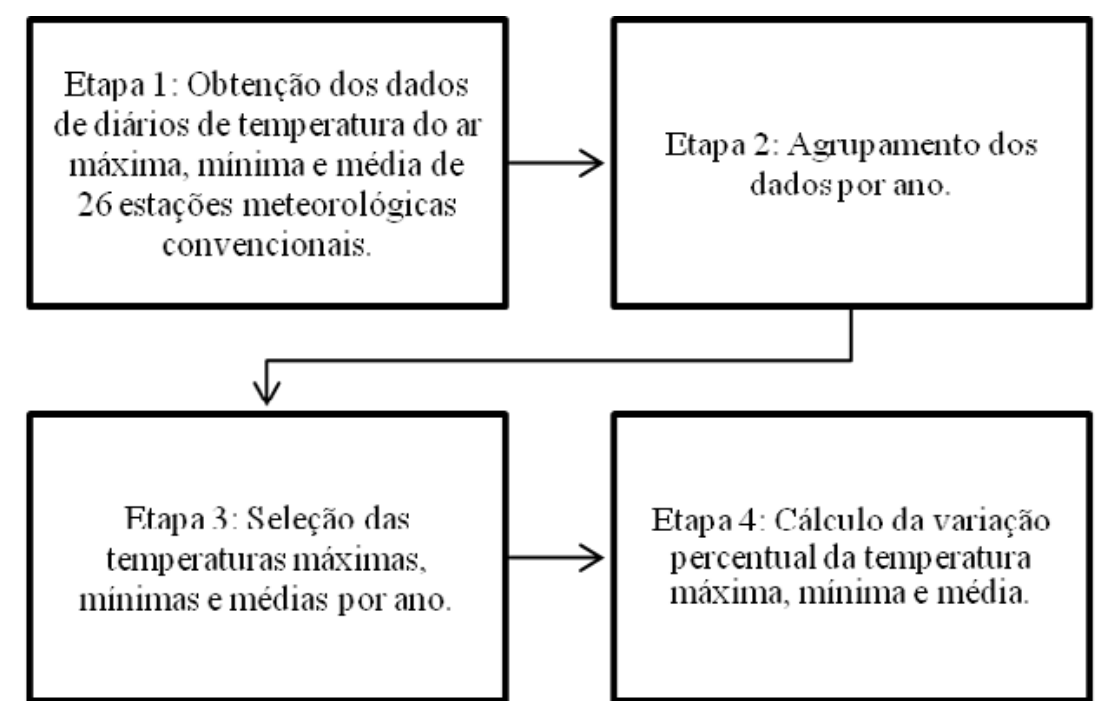

elaboração: Os autores.

Como já destacado, na primeira etapa, obtiveram-se os dados brutos de temperatura junto ao INMET, por meio do banco de dados da instituição, disponível no sítio eletrônico 
da mesma. Vale salientar que, neste trabalho, não foram aplicados aos dados métodos de preenchimentos de falhas nem de análise de consistência. Foram utilizados dados brutos para verificar a aplicabilidade da técnica de anos-padrão para dados de temperatura do ar. Contudo, para as próximas etapas da pesquisa, serão utilizadas técnicas de preenchimento de falhas e análise de consistência.

Na segunda etapa, os dados foram agrupados e tabulados por ano e por estação, por meio de planilha eletrônica possibilitando, assim, a execução da terceira etapa, quando elencou-se a temperatura máxima, mínima e média anual.

$\mathrm{Na}$ quarta etapa definiu-se a variação percentual da temperatura máxima, mínima e média em relação à média, tendo como base a técnica de anos-padrão descrita anteriormente, para tanto utilizou-se a fórmula a seguir:

$$
\operatorname{Var}(\%)=\frac{x-\bar{X}}{A B S(x)} 100
$$

onde:

$\operatorname{Var}(\%)$ : variação percentual

$x$ : temperatura extrema (máxima ou mínima) ou média do ano

$\bar{X}$ : média das temperaturas extremas (máxima ou mínima) ou média

$A B S$ : valor absoluto da temperatura extrema (máxima ou mínima) ou média do ano

Com base nos resultados da variação percentual foram tabulados os dados de temperatura máxima, mínima e média por ano e sua respectiva variação percentual em relação a média.

Os resultados foram espacializados permitindo a elaboração de 12 mapas. Para elaboração dos mapas foi utilizado o software ArcGis 10.2, tendo como bases cartográficas arquivos vetoriais disponibilizados pela Agência Nacional de Águas (ANA), bem como arquivos raster (SRTM) da Empresa Brasileira de Agropecuária (Embrapa).

\section{Resultados e discussões}

Com o intuito de compreender a forma como os dados das 26 estações foram tratados, a tabela 1 apresenta os dados da estação meteorológica de Brasília como exemplo, bem como o tratamento dos mesmos. Esse exemplo, refere-se às temperaturas extremas e média dessa estação no decorrer da série histórica. Na mesma tabela, é apresentada a variação percentual em relação a média. 


\section{Tabela 1}

Extremos de temperatura e temperatura média e suas respectivas variações percentuais na estação Brasília-DF.

\begin{tabular}{ccccccc}
\hline Ano & Temp. Máx Var. percentual Temp. Mín Var. percentual & Temp. Méd Var. percentual \\
\hline 1980 & 33,40 & 2,24 & 11,40 & 22,27 & 20,63 & $-1,99$ \\
\hline 1981 & 33,00 & 1,02 & 6,60 & $-29,21$ & 20,30 & $-3,54$ \\
\hline 1982 & 31,60 & $-3,27$ & 10,80 & 15,84 & 20,46 & $-2,77$ \\
\hline 1983 & 31,20 & $-4,49$ & 8,60 & $-7,76$ & 20,66 & $-1,84$ \\
\hline 1984 & 31,80 & $-2,66$ & 9,10 & $-2,40$ & 20,86 & $-0,90$ \\
\hline 1985 & 31,30 & $-4,19$ & 3,30 & $-64,61$ & 20,34 & $-3,35$ \\
\hline 1986 & 32,20 & $-1,43$ & 10,10 & 8,33 & 20,83 & $-1,01$ \\
\hline 1987 & 32,60 & $-0,21$ & 8,70 & $-6,69$ & 21,28 & 1,11 \\
\hline 1988 & 33,20 & 1,63 & 8,30 & $-10,98$ & 20,76 & $-1,37$ \\
\hline 1989 & 31,60 & $-3,27$ & 9,40 & 0,82 & 20,56 & $-2,29$ \\
\hline 1990 & 31,60 & $-3,27$ & 7,00 & $-24,92$ & 20,85 & $-0,92$ \\
\hline 1991 & 30,80 & $-5,72$ & 9,50 & 1,89 & 20,40 & $-3,08$ \\
\hline 1992 & 30,00 & $-8,17$ & 11,10 & 19,05 & 20,17 & $-4,17$ \\
\hline 1993 & 31,40 & $-3,88$ & 8,90 & $-4,54$ & 20,98 & $-0,31$ \\
\hline 1994 & 33,70 & 3,16 & 6,60 & $-29,21$ & 21,12 & 0,35 \\
\hline 1995 & 32,90 & 0,71 & 9,90 & 6,18 & 21,19 & 0,68 \\
\hline 1996 & 32,70 & 0,10 & 6,90 & $-25,99$ & 21,11 & 0,32 \\
\hline 1997 & 33,10 & 1,32 & 8,00 & $-14,20$ & 20,93 & $-0,56$ \\
\hline 1998 & 33,50 & 2,55 & 10,10 & 8,33 & 21,93 & 4,20 \\
\hline 1999 & 32,30 & $-1,13$ & 9,00 & $-3,47$ & 21,24 & 0,90 \\
\hline 2000 & 32,50 & $-0,51$ & 8,20 & $-12,05$ & 21,05 & 0,03 \\
\hline 2001 & 32,60 & $-0,21$ & 11,10 & 19,05 & 21,08 & 0,17 \\
\hline 2002 & 33,10 & 1,32 & 11,20 & 20,13 & 21,73 & 3,23 \\
\hline 2003 & 33,30 & 1,94 & 10,30 & 10,47 & 21,32 & 1,32 \\
\hline 2004 & 33,60 & 2,85 & 9,40 & 0,82 & 21,05 & 0,04 \\
\hline 2005 & 33,80 & 3,47 & 10,20 & 9,40 & 21,48 & 2,04 \\
\hline 2006 & 32,70 & 0,10 & 10,80 & 15,84 & 21,16 & 0,52 \\
\hline 2007 & 34,30 & 5,00 & 10,90 & 16,91 & 21,77 & 3,46 \\
\hline 2008 & 35,80 & 9,59 & 10,60 & 13,69 & 21,34 & 1,38 \\
\hline 2009 & 31,80 & $-2,66$ & 9,80 & 5,11 & 21,33 & 1,35 \\
\hline 2010 & 33,20 & 1,63 & 9,40 & 0,82 & 21,64 & 2,83 \\
\hline 2011 & 33,40 & 2,24 & 11,10 & 19,05 & 21,16 & 0,56 \\
\hline 2012 & 33,70 & 3,16 & 11,80 & 26,56 & 21,40 & 1,70 \\
\hline 2013 & 33,00 & 1,02 & 8,90 & $-4,54$ & 21,45 & 1,91 \\
\hline Média & 32,67 & & 9,32 & & 21,05 & \\
\hline Máximo & 35,80 & 9,59 & 11,80 & 26,56 & 21,93 & 4,20 \\
\hline Mínimo & 30,00 & $-8,17$ & 3,30 & $-64,61$ & 20,17 & $-4,17$ \\
\hline & & & & & & \\
\hline 190 & & & & & \\
\hline & & & & & & \\
\hline
\end{tabular}

fonte: INMET ([s.d]).

A partir dos dados de temperatura do ar registrados nas estações referentes à área de estudo, foram elaborados 12 mapas, para tanto foi utilizado o software ArcGis 10.2. O método de interpolação utilizado foi a krigagem seguindo as orientações de Gardiman Junior e outros (2012) e Souza (2011) que, ao compararem os métodos de interpolação de dados, concluíram que a krigagem apresentou melhor desempenho. Esse método, 
segundo Gallardo (2006³ apud Gardiman Junior et al.) é baseado numa função contínua, que explica o comportamento de uma variável nas distintas direções de um espaço geográfico. Permite associar a variabilidade da estimação com base na distância que existe entre um par de pontos, pelo uso de um semivariograma, o qual permite verificar o nível de similitude que existe entre estes, à medida que se afastam. A seguir são apresentados mapas referentes à espacialização das temperaturas máximas e suas variações.

\section{Figura 5}

Espacialização das temperaturas máximas e suas variações na bacia do rio Paranaíba $(5 \mathrm{a}, 5 \mathrm{~b}, 5 \mathrm{c}, 5 \mathrm{~d})$

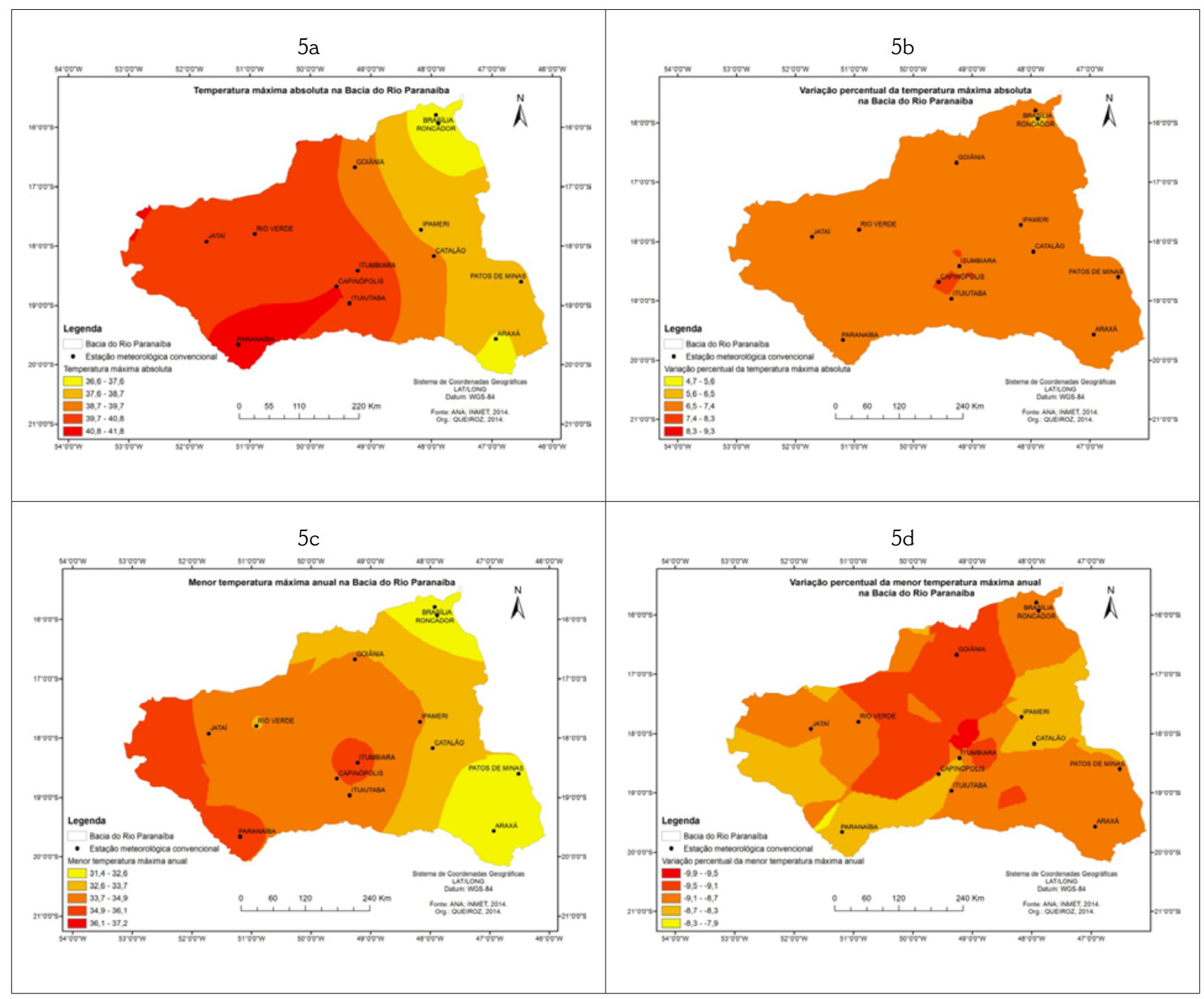

fonte: INMET ([s.d]) e ANA ([s.d]). elaboração: Os autores.

3 GAllardo, A. Geostadística. Ecosistemas, Móstoles, v. 15, n. 3, p. 1-11, 2006. 
Na Figura 5a (mapa de distribuição espacial das temperaturas máximas na área de estudo), observa-se que as temperaturas mais elevadas foram registradas na parte oeste da bacia, sobretudo na porção sudoeste, atingindo $41,8^{\circ} \mathrm{C}$. Já na porção leste da bacia, as maiores temperaturas registradas foram entre $36,6^{\circ} \mathrm{C}$ e $38,7^{\circ} \mathrm{C}$. Constatou-se que as menores temperaturas máximas absolutas são registradas a leste, onde predominam as altitudes superiores a 1.000 metros, e os maiores valores são encontrados na porção oeste, em altitudes entre 375 a 750 metros.

Vale destacar que a porção oeste é caracterizada por relevo plano, com baixas altitudes, sobretudo, próximo ao médio e baixo curso do rio Paranaiba. Já o relevo da parte leste da bacia pode ser descrito como de planalto com a ocorrência de chapadas localizadas nas regiões de maiores altitudes, ultrapassando 1.000 metros, como observado na Figura 3.

Já com relação à variação espacial percentual da temperatura máxima absoluta anual em relação à média (Figura $5 b$ ), observa-se que as maiores variações em relação à média de temperatura máxima foram registradas na porção centro-sul da bacia, apresentando variação de até $8,3 \%$. E a menor variação ocorreu na porção nordeste da bacia, atingindo $5,6 \%$ de variação em relação à média.

Com relação à espacialização das menores temperaturas máximas absolutas anuais registradas em cada estação ao longo da bacia (Figura 5c), nota-se a existência de duas áreas em que se registraram os índices mais elevados no que tange as menores temperaturas máximas (em torno de $37^{\circ} \mathrm{C}$ ), sendo uma na parte oeste da bacia, e outra na sua parte central. Já na porção sudeste e nordeste foram registradas as menores temperaturas máximas, com valores próximos a $30^{\circ} \mathrm{C}$. Portanto, verificou-se que, na série em questão, as menores temperaturas máximas absolutas anuais elevam-se de sudeste e nordeste para oeste.

Na Figura 5d, é possível ver a variação percentual da menor temperatura máxima anual de cada estação em relação a média, sendo que as maiores variações ocorreram na porção central da bacia, registrando variação de até $-9,9 \%$. Já a parte com menor variação ocorreu na porção sudoeste da bacia, com variação de $-7,9 \%$ em relação à média. Ainda sobre a variação percentual da menor temperatura máxima anual, nota-se que a diferença entre o menor e maior valor foi baixo, havendo, assim, uma pequena variação.

Verifica-se uma forte influencia da altitude nos registros de temperaturas máximas na bacia, o que corrobora as afirmações de Fritzsons, Mantovani e Aguiar (2008):

A temperatura do ar é influenciada também pela altitude, latitude e longitude e, normalmente, decresce com a elevação da altitude numa proporção de aproximadamente $1^{\circ} \mathrm{C} / 100 \mathrm{~m}$ (gradiente adiabático do ar seco). [... . Assim, nos trópicos, as grandes diferenças de temperatura em pequenas distâncias são principalmente decorrentes dos efeitos da variação da altitude e nebulosidade e não da latitude, podendo haver também grandes diferenças nas condições de temperatura entre os locais a barlavento e os situados a 
sotavento de uma montanha (Ometto, $1981^{4}$ apud Fritzsons; Mantovani; Aguiar, 2008, p. 49-50)

Tendo em vista o que foi supracitado e com base nas Figuras 3, 5a e 5c, é possível afirmar que na bacia do rio Paranaíba a hipsometria pode ser considerada um fator geográfico determinante para a definição das áreas com temperaturas máximas anuais mais elevadas, bem como as mais baixas.

Na sequência, são apresentados mapas referentes à espacialização das temperaturas médias anuais e suas variações.

\section{Figura 6}

Espacialização das temperaturas médias anuais e suas variações na bacia do rio Paranaíba (6a, 6b, 6c, 6d)

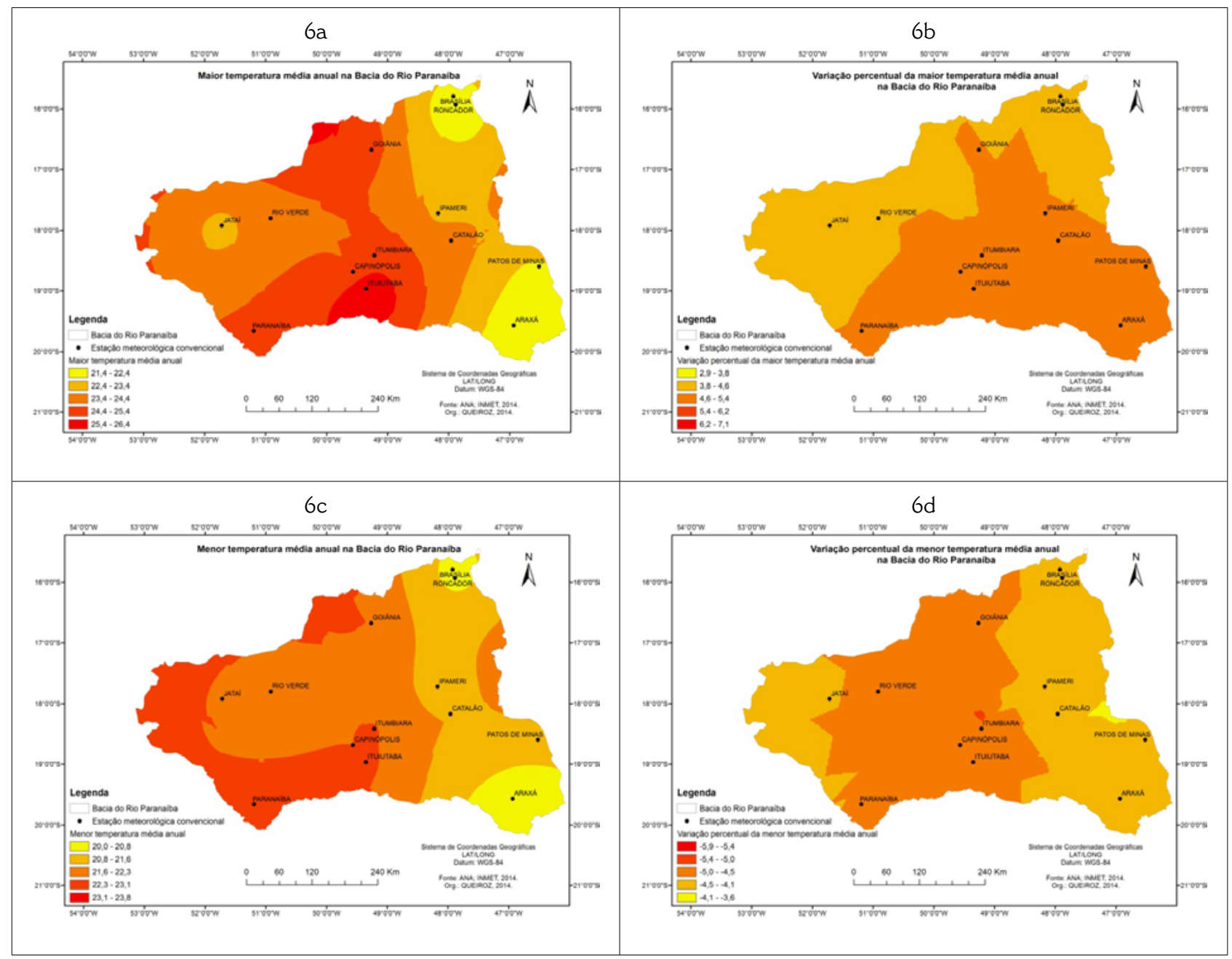

fonte: INMET ([s.d]) e ANA ([s.d]). elaboração: Os autores.

4 OMETTO, J. C. Bioclimatologia vegetal. São Paulo: Ceres, 1981. p. 129-132. 
A seguir serão apresentados os resultados da avaliação da distribuição espacial realizada com os dados de temperatura média anual. A Figura 6a apresenta a espacialização das maiores temperaturas médias anuais na bacia. Verificou-se que as maiores temperaturas médias foram registradas na porção centro-sul, atingindo $26,4^{\circ} \mathrm{C}$. Já na porção nordeste e sudeste da bacia, as maiores temperaturas médias registradas ficaram em entre $21,4{ }^{\circ} \mathrm{C}$ e $22,4^{\circ} \mathrm{C}$, sendo os menores índices. Portanto, observa-se, principalmente, um crescimento da temperatura média anual de leste para a porção central.

Como mostra a Figura 6b, referente a variação percentual da maior temperatura média anual em relação a média, as maiores variações ocorreram na porção sul da bacia, registrando variação de até $5,4 \%$. Em contrapartida, a parte norte da bacia apresenta menor variação, de 3,8\% a 4,6\% de variação em relação à média.

Com relação à menor temperatura média na bacia do rio Paranaíba (Figura 6c) observa-se que os menores valores foram registrados nas porções sudeste e nordeste, com temperatura de 20 a $20,8^{\circ} \mathrm{C}$. A porção que apresenta índices mais elevados da menor temperatura média situam-se na parte centro-norte, sudoeste e oeste com a menor temperatura média em torno de 22,3 a $23,8^{\circ} \mathrm{C}$.

Já a Figura 6d mostra que existe uma tendência a homogeneidade na variação percentual da menor temperatura média anual na bacia (de -3,6 a-5, $9 \%$ ), com predomínio da faixa de $-4,1$ a $5 \%$ de variação.

Sobre os extremos da temperatura média na área de estudo, pode-se observar que, assim como a temperatura máxima, o relevo exerce grande influência na temperatura média. Sobre essa estrita relação das temperaturas máximas e médias, é possível afirmar que esse fato ocorre porque a bacia está na região de clima tropical, ou seja, com predominância de registro de altas temperaturas.

Em seguida serão apresentados os resultados para a espacialização dos dados referentes aos extremos de temperatura mínima na bacia do rio Paranaíba. Na Figura 7a é possível observar a espacialização da maior temperatura mínima anual na bacia, sendo que neste caso nota-se uma nítida relação com a latitude, quando a temperatura aumenta de sul para norte, a menor $8,6^{\circ} \mathrm{C}$ até $13,6^{\circ} \mathrm{C}$.

$\mathrm{Na}$ Figura $7 \mathrm{~b}$, observa-se uma delimitação da variação percentual da maior temperatura mínima anual, sendo que os valores mais elevados encontram-se na porção sul e oeste, com valores atingindo variação de até $139,9 \%$ ao longo do período analisado. Já as menores variações percentuais da maior temperatura mínima situam-se na porção leste e norte (19,7 a 43,7\%).

Ao analisar a Figura $7 \mathrm{c}$, verifica-se que as menores temperaturas foram registradas nas porções sul e oeste da bacia, atingindo até $-1{ }^{\circ} \mathrm{C}$ durante o período analisado. Já as maiores temperaturas mínimas absolutas foram registradas na parte nordeste da bacia com até $4,9^{\circ} \mathrm{C}$. 
Figura 7

Espacialização das temperaturas mínimas e suas variações na bacia do rio Paranaíba (7a, 7b, 7c, 7d)

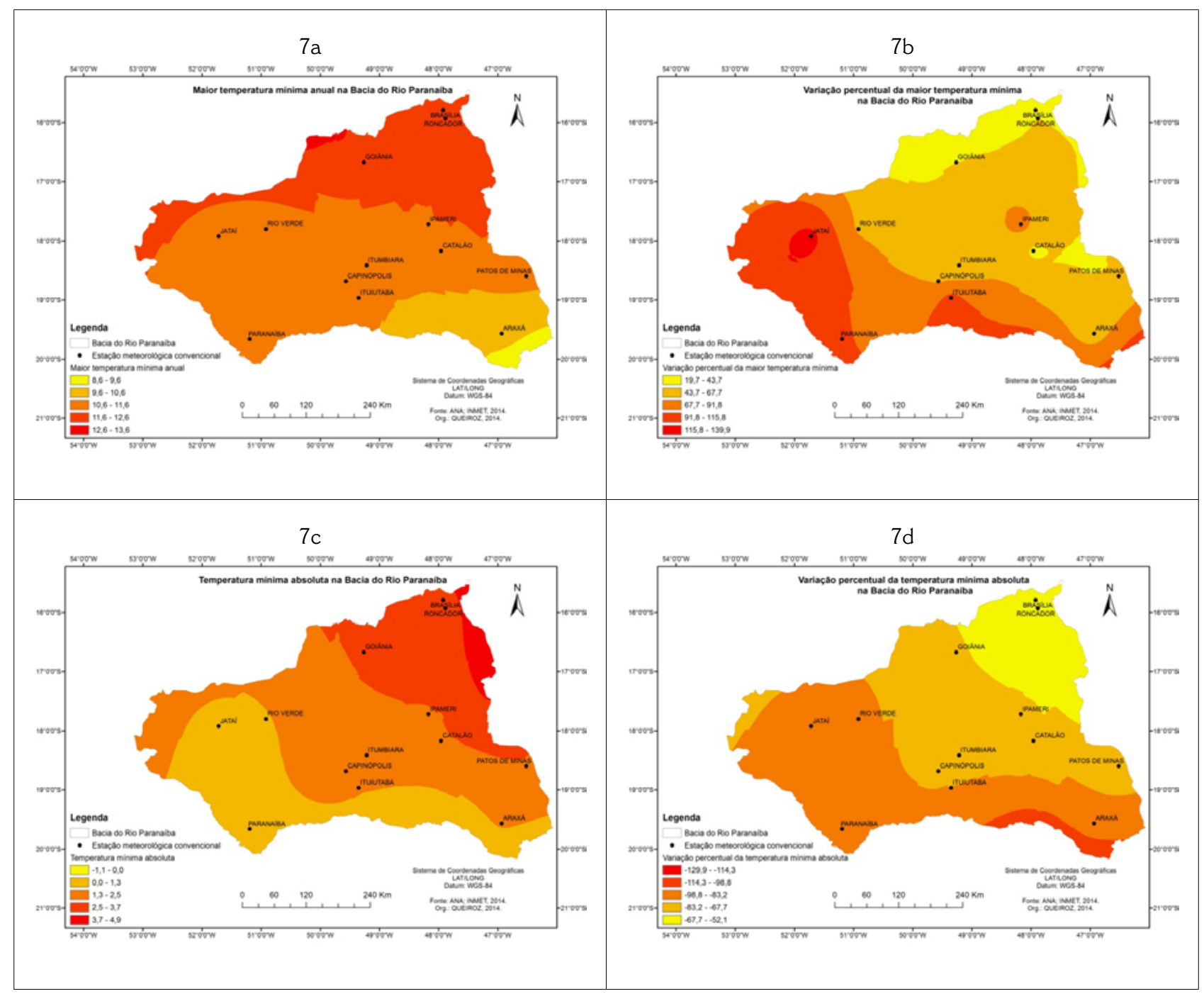

fonte: INMET ([s.d]) e ANA ([s.d]). elaboração: Os autores.

$\mathrm{Na}$ Figura 7d, é possível ver a variação percentual da temperatura mínima absoluta anual em relação a média na bacia, sendo registrado temperaturas com variação de até $-129,9 \%$ abaixo da média das mínimas absolutas na porção sudeste da bacia. Já as menores variações ocorreram no setor nordeste com $-52,1 \%$.

A espacialização das temperaturas mínimas e suas variações mostrou que a estrutura espacial tem estreita relação com três fatores climáticos: a dinâmica das massas de ar, o relevo e a latitude. De forma detalhada, observou-se que a porção sul e sudoeste registraram as menores temperaturas por situar-se em latitudes mais elevadas, o que determina maior influência da massa polar atlântica conforme Monteiro (1969). Além disso, o relevo na bacia tem papel fundamental na dispersão e/ou retenção do ar frio ao 
longo da bacia, tendo em vista que a parte sudoeste encontra-se sobre áreas planas que se estendem desde o Mato Grosso do Sul adentrando ao sudoeste goiano, o que facilita a disseminação desse ar frio pela região.

Já no Triângulo Mineiro e na porção goiana adjacente (Sul Goiano), o ar frio também é influenciado pelo relevo, no entanto, neste caso, a calha dos grandes rios forma um "corredor" que facilita o deslocamento do ar frio até que o mesmo perca intensidade, conforme Mendes e Queiroz (2011) relatam sobre a dinâmica das frentes frias. No caso do Triângulo Mineiro, comumente o ar frio avança pela calha do rio Paraná adentrando pelo vale do rio Paranaíba. (Mendes; Queiroz, 2011, p. 344).

A distribuição espacial da temperatura mínima absoluta (Figura $7 \mathrm{c}$ ) pode ser correlacionada com a descrição da trajetória da Frente Polar de Fonzar (1994):

A Frente Polar tem, frequentemente, o sentido NW/SE, por isso quando há algum sistema atuando no Sul brasileiro, a entrada pelo interior é rápida e as baixas temperaturas são sentidas em Cuiabá antes, ou ao mesmo tempo, que em Goiânia e, depois, em São Paulo (Fonzar, 1994, p. 30).

O sentido NW/SE corresponde à direção de sequência de faixas de temperatura mínima absoluta representada na Figura 7c, sendo a frente polar o principal fenômeno atmosférico responsável pela ocorrência da temperatura mínima absoluta na bacia.

Ainda sobre as temperaturas mínimas, Nimer (19795 apud Barros 2003) destaca importantes características climáticas da região Centro-Oeste, onde está a maior parte da área da bacia:

Nimer (1979) explica que as temperaturas baixas do inverno nesta área estão relacionadas à ação direta do poderoso anticiclone polar, sucedendo à passagem de frentes frias (KF) que, ao transporem a Cordilheira dos Andes, produzem, na zona frontal, uma advecção do ar tropical. $O$ interior da região Centro-Oeste, que estava sob calmarias, passa, então, a apresentar ventos NE e NW, que resultam na imediata elevação das temperaturas máximas. Diante de tal aumento de temperatura, a umidade do ar cai a valores muito baixos e, com a chegada da frente sobre o lugar, o céu fica coberto de nuvens de convecção dinâmica (cúmulos e cúmulos-nimbo), ocorrendo chuvas (ainda que pouco intensas) e trovoadas. Novamente com relação às temperaturas na região, quedas bruscas durante dois dias podem ocorrer devido aos avanços do anticiclone polar. Embora a passagem de frentes frias seja muito comum no inverno, esse fenômeno, que Nimer (1979) chama de friagem, não é muito frequente (Barros, 2003, p. 104).

5 NIMER, E. Climatologia do Brasil. Rio de Janeiro: IBGE, 1979. (Série Recursos Naturais e Meio Ambiente.) 
Ao analisar os 12 mapas referentes aos extremos de temperatura, observa-se que a maior diferença entre a temperatura máxima absoluta e mínima absoluta ocorre na porção sudoeste, sendo registrado tanto as maiores temperaturas anuais como as menores. Essa dinâmica da bacia pode ser compreendida tendo em vista dois fatores geográficos. O primeiro diz respeito à hipsometria da bacia (Figura 3), com altitude mais baixa na porção sudoeste, na direção de seu exutório. Isso faz com que as maiores temperaturas máximas e médias sejam registradas na porção sul e oeste, ou seja, na região com menor altitude. Ao analisar a relação da temperatura do ar com a altitude, no Centro-Oeste, Barros (2003) destaca que:

[...] através da altitude, faz com que as mais altas chapadas sedimentares e superfícies cristalinas do centro-sul da região possuam temperatura média anual entre $20^{\circ}$ a $22^{\circ} \mathrm{C}$, podendo chegar a menos de $20^{\circ} \mathrm{C}$ no Distrito Federal, que apresenta altitudes acima de 1.200 m. (Barros, 2003, p. 103)

Já o segundo fator geográfico de grande influência na variação das temperaturas do ar, principalmente na temperatura mínima, é a dinâmica das massas de ar, sobretudo a massa fria $(\mathrm{mPa})$. Em função do relevo e da localização geográfica, a entrada da $\mathrm{mPa}$, na região da bacia, ocorre pela porção sudoeste, o que favorece a queda mais acentuada da temperatura mínima absoluta nesta região e, conforme a massa de ar se desloca em direção a porção nordeste, ela perde força, pois se depara com a barreira promovida pela elevação da altitude, mostrado na Figura 9. As Figuras 8 e 9 representam o perfil topográfico da bacia e o traçado do perfil no mapa hipsométrico, estendendo desde o seu exutório, em Paranaíba (menor altitude), até o nordeste da bacia, em Brasília, região de maior altitude.

\section{Figura 8}

Perfil topográfico na bacia, estendendo desde Paranaíba até Brasília, traçado do perfil e da hipsometria da bacia $(8 \mathrm{a}, 8 \mathrm{~b})$

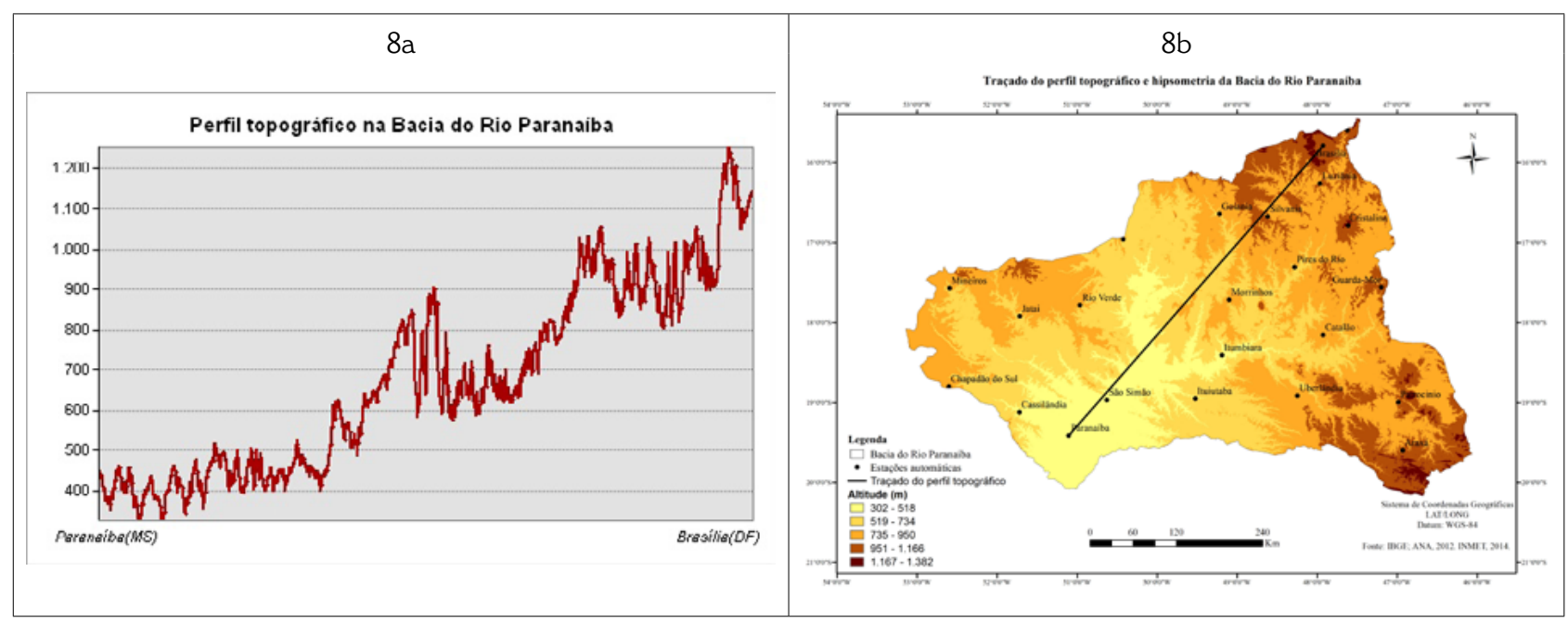

fonte: ANA ([s.d]), IBGE ([s.d]) e SRTM-Embrapa (Miranda, 2005).

elaboração: Os autores. 
A utilização da técnica da variação percentual foi essencial para identificar os extremos de temperatura do ar. Por meio desta técnica foi possível analisar a variabilidade dos extremos de temperatura ao longo do período analisado podendo, dessa maneira, ver em que região a oscilação da temperatura foi maior. Essa informação é de grande utilidade, pois apesar dos avanços técnico-científicos, o clima ainda é referência nas atividades agrícolas, afetando os estágios de produção, incluindo a preparação da terra, semeadura, crescimento dos cultivos, colheitas, armazenamento, transporte e comercialização, tendo em vista que a prática agrícola fundamenta-se quase que exclusivamente nas técnicas a céu aberto, ou seja, não se utilizam de irrigação. E como a região em estudo tem grande vocação agropecuária, uma investigação dessa natureza pode ser utilizado como suporte para auxiliar na elaboração de um diagnóstico de condições ambientais, justificando ou não, as necessidades da intervenção do Estado, nesse setor da economia, por meio de políticas públicas destinadas a amenizar os efeitos negativos decorrentes de variáveis meteorológicas.

\section{Considerações finais}

A partir dos resultados, pode-se afirmar que a metodologia de espacializar os extremos de temperatura do ar máxima, média e mínima, utilizando uma adaptação da técnica de anos-padrão, foi muito útil para compreender a variabilidade espacial dos dados sobre a área de estudo. Por meio dos dados de variação percentual dos extremos de temperatura do ar, foi possível compreender sua dinâmica espacial ao longo do período analisado, ou seja, identificar qual porção do território analisado tem maior variabilidade temporal do parâmetro.

Pela técnica da variação percentual, os resultados das análises da temperatura mostraram que a bacia apresenta setores em conformidade com a altimetria e também com relação a sua disposição na entrada dos sistemas atmosféricos, sobretudo a massa polar atlântica, principal fator geográfico que influencia o campo térmico da região.

Dessa forma, conclui-se que essa técnica se mostrou eficaz para compreender a variabilidade temporal na área da bacia do rio Paranaíba.

\section{Referências}

AB'SÁBER, A. N. Os domínios de natureza no Brasil: potencialidades paisagísticas. São Paulo: Ateliê, 2003.

ANA. AGÊNCIA NACIONAL DE ÁGUAS. Plano de recursos hídricos e do enquadramento dos corpos hídricos superficiais da bacia hidrográfica do rio Paranaíba. Brasília: ANA, 2013. Disponível em: http://cbhparanaiba.org.br/ prh-paranaiba/plano. Acesso em: 10 set. 2013.

AGÊNCIA NACIONAL DE ÁGUAS. Disponível em: $\underline{w w w . a n a . g o v . b r}$. Acesso em: 3 out. 2014. 
ANDRADE, S. F. Estudo de estratégias bioclimáticas no clima de Florianópolis. Dissertação (Mestrado em Engenharia) - Centro Tecnológico, Universidade Federal de Santa Catarina, Florianópolis, 1996.

AYOADE, J. O. Introdução à climatologia para os trópicos. Trad. Maria Juraci Zani dos Santos. Rio de Janeiro: Bertrand Brasil, 2010.

BARROS, J. R. A chuva no Distrito Federal: o regime e as excepcionalidades do ritmo. Dissertação (Mestrado em Geografia) - Instituto de Geociências e Ciências Exatas, Universidade Estadual Paulista, Rio Claro, 2003.

; ZAVATTINI, J. A. Bases conceituais em climatologia geográfica. Mercator, Fortaleza, v. 8, n. 16, p. 255-261, 2009.

BOIN, M. N. Chuvas e erosões no Oeste Paulista: uma análise climatológica aplicada. Tese (Doutorado em Geociências e Meio Ambiente) - Instituto de Geociências e Ciências Exatas, Universidade Estadual Paulista, Rio Claro, 2000.

COSTA, A. C. L. et al. Distribuição geoespacial e horária da temperatura do ar na cidade de Belém, estado do Pará, Brasil. Brazilian Geographical Journal, Ituiutaba, MG, v. 4, n. 1, p. 150-168, jan./jun. 2013.

DINIZ, J. A. F. Classificação de uma variável e sua aplicação na geografia. Boletim de Geografia Teorética, Rio Claro, n. 1, p. 25-39, 1971.

FONZAR, B. C. A circulação atmosférica na América do Sul: os grandes sistemas planetários e subsistemas regionais que atingem o continente - localização e trajetórias. Caderno de Geociências, Rio de Janeiro, n. 11, p. 11-33, 1994.

FRITZSONS, E.; MANTOVANI, L. E.; AGUIAR, A. V. Relação entre altitude e temperatura: uma contribuição ao zoneamento climático no estado do Paraná. REA - Revista de estudos ambientais, Blumenau, v. 10, n. 1, p. 49-64, 2008.

GARDIMAN JUNIOR, B. S. et al. Análise de técnicas de interpolação para espacialização da precipitação pluvial na bacia do rio Itapemirim (ES). Ambiência, Guarapuava, PR, v. 8, p. 61-71, 2012.

IBGE. INSTITUTO BRASILEIRO DE GEOGRAFIA E ESTATÍSTICA. Disponível em: http://www.ibge.gov.br. Acesso: 17 set. 2012.

INMET. INSTITUTO NACIONAL DE METEOROLOGIA. Disponível em: 
www.inmet.gov.br. Acesso em: 10 mar. 2014.

MENDES, P. C. Gênese e estrutura espacial das chuvas na cidade de UberlândiaMG. Dissertação (Mestrado em Geografia) - Instituto de Geografia, Universidade Federal de Uberlândia, Uberlândia, 2001.

; QUEIROZ, A. T. Caracterização climática do município de Ituiutaba-MG. In: PORTUGUeZ, A. P.; MOURA, G. G.; COSTA, R. A. (Org.). Geografia do Brasil Central: enfoques teóricos e particularidades regionais. Uberlândia, MG: Assis Editora, 2011. p. 333-354.

MIRANDA, E. E. (Coord.). Brasil em Relevo. Campinas: Embrapa, 2005. Disponível em: http://www.relevobr.cnpm.embrapa.br. Acesso em: 13 jul. 2014.

MONTEIRO, C. A. F. A Frente Polar Atlântica e as chuvas de inverno na fachada sul oriental do Brasil. (Contribuição metodológica à análise rítmica dos tipos de tempo no Brasil.) São Paulo: Instituto de Geografia da USP, 1969. (Série Teses e Monografias n. 1).

A dinâmica climática e as chuvas no estado de São Paulo: estudo geográfico sob forma de atlas. São Paulo: USP, 1973.

MONTEIRO, A.; CARVALHO, V. Clima e planejamento regional. In: AMORIM, M. C. C. T.; SANT'ANNA NETO, J. L.; MONTEIRO, A. (Org.). Climatologia urbana e regional: questões teóricas e estudos de caso. São Paulo: Outras Expressões, 2013. p. 93-116.

SANCHEZ, M. C. A problemática de intervalos de classes na elaboração de cartogramas. Boletim de Geografia Teorética, Rio Claro, SP, v. 4, p. 53-65, 1972.

SCHNEIDER, H.; SILVA, C. A. O uso do modelo box plot na identificação de anospadrão secos, chuvosos e habituais na microrregião de Dourados, Mato Grosso do Sul. Revista do Departamento de Geografia, São Paulo, v. 27, p. 131-146, 2014.

SILVESTRE, M. R.; SANT'ANNA NETO, J. L.; FLORES, E. F. Critérios estatísticos para definir anos-padrão: uma contribuição à climatologia geográfica. Revista Formação, v. 2, n. 20, p. 23-53, 2013.

SORRE, M. Objeto e método da climatologia. Revista do Departamento de Geografia, São Paulo, v. 18, p. 89-94, 2006. 
SOUZA, J. L. L. L. et al. Avaliação de métodos de interpolação aplicados à espacialização das chuvas no território identidade Portal do Sertão-BA. In: SIMPÓSIO BRASILEIRO DE SENSORIAMENTO REMOTO, 15., 2011, Curitiba. Anais... São José dos Campos-SP: MCT/INPE, 2011. p. 4295-4302.

TAVARES, A. C. Critérios de escolha de anos-padrões para análise rítmica em climatologia. Geografia, Rio Claro, v. 1, n. 1, p. 79-87, 1976. 